\title{
Bridgeless CUK Rectifier with Output Voltage Regulation using Fuzzy controller
}

\author{
Krishnendu.R.V ${ }^{1}$, Sunil Kumar.P.R ${ }^{2}$ \\ ${ }^{1}$ (Electrical and Electronics Engineering, Govt.Engineering College Idukki/M.G.University, India) \\ 2 (Electrical and Electronics Engineering, Govt.Engineering College Idukki / M.G.University, India)
}

\begin{abstract}
A bridgeless single-phase AC to DC Power Factor Correction (PFC) rectifiers based on CUK topology is discussed in this paper. Compared to the conventional converter the bridgeless circuit lack the input diode bridge. Only two semiconductors is working during one switching cycle and hence the conduction losses are minimised. CUK PFC rectifier is designed to work in Discontinuous Conduction Mode (DCM) to achieve almost a unity power factor and low total harmonic distortion of the input current. The DCM operation gives additional advantages such as zero-current turn-ON in the power switches, zero-current turn-OFF in the output diode, and simple control circuitry. Bridgeless circuit performance is analysed through simulation. In this paper simulation of the bridgeless CUK rectifier for output regulation is done. The voltage mode control loop compares the actual output voltage with the reference voltage of $40 \mathrm{~V}$ to maintain the output constant at this value. A conventional fuzzy controller is used in this control loop which provides good regulation.
\end{abstract}

\section{INTRODUCTION}

The input supply voltage for a power electronic application is a $\mathrm{AC}$ sine wave of frequency $50 \mathrm{~Hz}$. This input should be converted to DC to enable the working of power electronic devices. The circuits which convert supply ac voltage to a particular dc voltage required by the power electronic devices are called rectifiers. Rectifiers with diodes and thyristors can be constructed and for these circuits large output capacitors are needed to reduce the output voltage ripple and these capacitors will be charged to the peak value of the input voltage. So the current will be large and discontinuous. Hence these rectifiers will draw highly distorted current from the supply and cause a low power factor.

In order to improve the power factor, many Power Factor Corrections (PFC) circuit are present such as active power factor correction and passive power factor correction. In passive PFC, passive elements like capacitors and inductors are introduced to improve the nature of the line current. An active PFC is a power electronic device designed to control the amount of power drawn by a load and obtains a power factor as close as possible to unity. Commonly any active PFC design functions by controlling the input current in order to make the current waveform follow the supply voltage waveform. The active power factor correction (PFC) circuits are widely used to effectively draw the energy from the mains via an AC to DC converter. These PFC circuits normally consists of full bridge diode rectifier and DC-DC converter.

The conventional power factor correction circuit consists of a $\mathrm{AC}$ to $\mathrm{DC}$ converter along with a $\mathrm{DC}$ to DC converter. The conventional circuit is shown in figure 1. The conventional power factor correction circuit contains a full bridge diode rectifier and a DC to DC converter connected to it. By adjusting the duty cycle of the switches in the DC to DC converter the power factor is improved. The disadvantage with this circuit is that the losses are high and the efficiency is lower. Losses are present in these circuits due to the voltage drop in the diode of the rectifier.

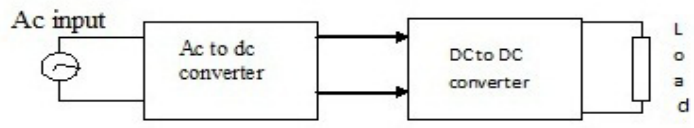

Figure 1: Basic power factor correction circuit

The losses can be reduced by eliminating the diode bridge. The circuit which does not have diode bridge is called bridgeless rectifiers. Here at every instant of the switching period the current flow through minimum number of power semiconductor switches. Accordingly, the converter conduction losses can be significantly reduced and higher efficiency can be obtained, as well as cost savings. Several bridgeless PFC rectifiers have been introduced using buck boost and SEPIC converter. Similar to the boost converter, the SEPIC converter has the disadvantage of discontinuous output current resulting in a relatively high output ripple [2]. Bridgeless circuits with boost converter and buck converters are present. In boost converter the dc output voltage is higher than the peak input voltage and it cannot be used for low power application such as for telecommunication [3]. By using the buck converter the input current does not track the input voltage at zero 
crossing of the input voltage [4]. Also, buck PFC converter results in an increased total harmonic distortion (THD) and a reduced power factor.

In my work bridgeless cuk rectifier is studied and simulated. The closed loop control of output voltage is done using fuzzy controller. The performance of the controller is verified.

\section{BRIDGELESS CUK RECTIFIER}

The bridgeless CUK converter is constructed by connecting two DC-DC CUK converters in parallel [1]. Here each converter operates for each half period of the input voltage. The bridgeless CUK converter is shown in figure 2 .

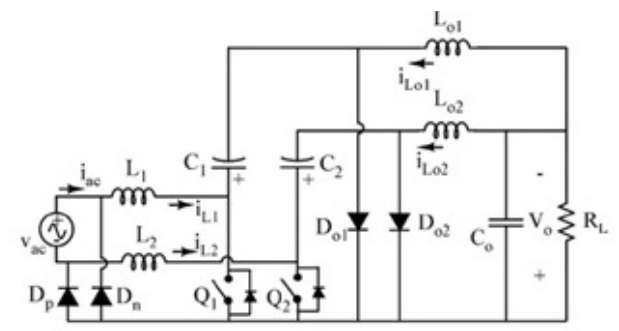

Figure 2: Bridgeless CUK rectifier

The circuit operation during the positive and negative half cycle of supply voltage period is shown in figure 3 .

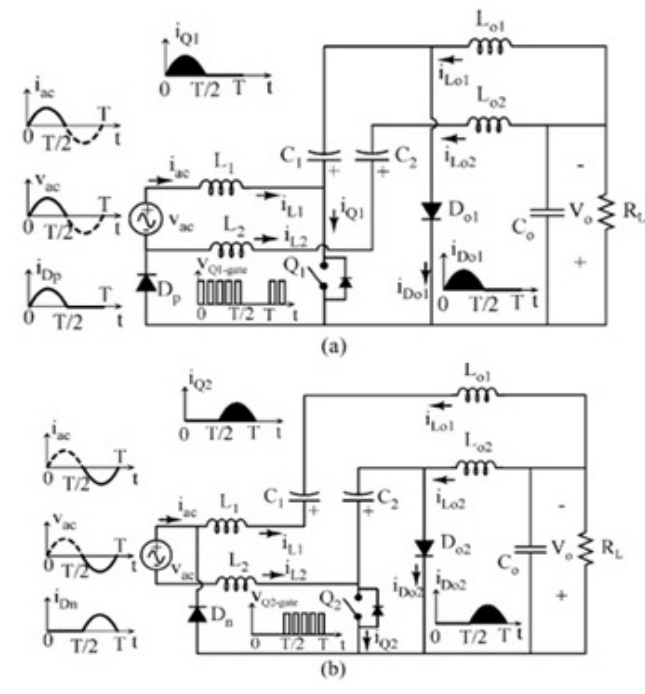

Figure 3: Converter operation a) during positive cycle b) during negative cycle

Here during the positive half cycle switch $\mathrm{Q}_{1}$ is turned on. The current flowing path during this half cycle of supply voltage is through $\mathrm{L}_{1}, \mathrm{Q}_{1}, \mathrm{C}_{1}$ and $\mathrm{D}_{01} . \mathrm{D}_{\mathrm{p}}$ is active during this cycle and it connects $\mathrm{AC}$ source to the output. During the negative half cycle switch $\mathrm{Q}_{2}$ is turned on. The current flowing path during the negative half cycle of supply voltage is through $\mathrm{L}_{2}, \mathrm{Q}_{2}, \mathrm{C}_{2}$ and $\mathrm{D}_{02}$. Dn is active during this cycle and it connects $\mathrm{AC}$ source to output. Here $D_{p}$ or $D_{n}$ connects the output voltage bus to input and thus common mode EMI noise emission can be eliminated.

Control signals for the switch $\mathrm{Q}_{1}$ and $\mathrm{Q}_{2}$ are shown in the figure 3. Here the two switches can be controlled by the same control signals and hence the control circuitry is simple.

\subsection{OPERATING PRINCIPLE}

The circuit operation during the positive and negative cycle of input voltage is same. Due to this symmetry of operation it is sufficient to analyze the circuit operation during any one half cycle ie, positive half cycle. For the analysis of the circuit certain assumptions are made:- Input voltage is sinusoidal, components are ideal, all capacitors are large enough to reduce switching voltage ripple.

The converter is operated in the Discontinuous Conduction Mode (DCM). There are several advantages for DCM mode of operation. These advantages include natural near-unity power factor, the power switches are turned ON at zero current, and the output diodes $\left(\mathrm{D}_{01}\right.$ and $\left.\mathrm{D}_{02}\right)$ are turned OFF at zero current. Thus, the losses due to the turn-ON switching and the reverse recovery of the output diodes are considerably reduced. 
Conversely, DCM operation significantly increases the conduction losses due to the increased current stress through circuit components. As a result, this leads to one disadvantage of the DCM operation, which limits its use to low-power applications. The circuit operation is divided into three distinct operating stages during one switching period. The modes of operation are:

Stage1: In this stage $\mathrm{Q}_{1}$ is turned on. The circuit operation is shown in figure 4. The current $\mathrm{V}_{\mathrm{C} 1}$ will flow through the switch and hence $D_{p}$ is forward biased. The diode $D_{01}$ is reverse biased by reverse voltage $\left(V_{a c}\right.$ $\left.+V_{0}\right) \cdot D_{02}$ is reverse biased by output voltage $V_{0}$. The current through inductors $i_{L 1}$ and $i_{L 01}$ increases linearly with input voltage. Current through inductor $\mathrm{i}_{\mathrm{L} 02}$ is zero due to constant voltage across $\mathrm{C}_{2}$. The inductor currents $\mathrm{i}_{\mathrm{L} 1}$ and $\mathrm{i}_{\mathrm{L} 01}$ are

$$
\mathrm{di}_{\mathrm{Ln}} / \mathrm{dt}=\mathrm{V}_{\mathrm{ac}} / \mathrm{L}_{\mathrm{n}} ; \mathrm{n}=1 ; 01
$$

The peak current through the active switch $\mathrm{Q} 1$ is given by

$$
\mathrm{I}_{\mathrm{Q} 1 ; \mathrm{pk}}=\left(\mathrm{V}_{\mathrm{m}} * \mathrm{D}_{1} * \mathrm{~T}_{\mathrm{s}}\right) / \mathrm{L}_{\mathrm{e}}
$$

where $V_{m}$ is the peak amplitude of the input voltage $V_{a c}, D_{1}$ is the switch duty cycle, and $L_{e}$ is the parallel combination of inductors $\mathrm{L}_{1}$ and $\mathrm{L}_{01}$.

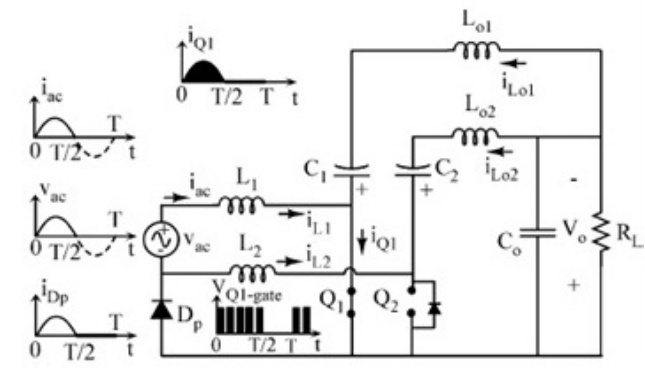

Figure 4: State 1 operation

Stage2:- In this stage switch $\mathrm{Q}_{1}$ is turned off. The circuit operation is shown in figure 5 . Diode $\mathrm{D}_{01}$ is turned on to provide path for inductor currents $i_{L 1}$ and $i_{L 01} . D_{p}$ is forward biased by the current $i_{L 1}$. This stage ends when the current through diode D01 is zero. The inductor currents are

$$
\mathrm{di}_{\mathrm{Ln}} / \mathrm{dt}=-\mathrm{V}_{0} / \mathrm{L}_{\mathrm{n}} ; \mathrm{n}=1 ; 01
$$

Stage3:- During this interval both the switch and diode are revere biased. The circuit operation is shown in figure 6 . The inductors act as a current source and hence voltage across the inductors is zero. The current $i_{L 1}$ charges the capacitor. This stage ends when $\mathrm{Q}_{1}$ is turned on.

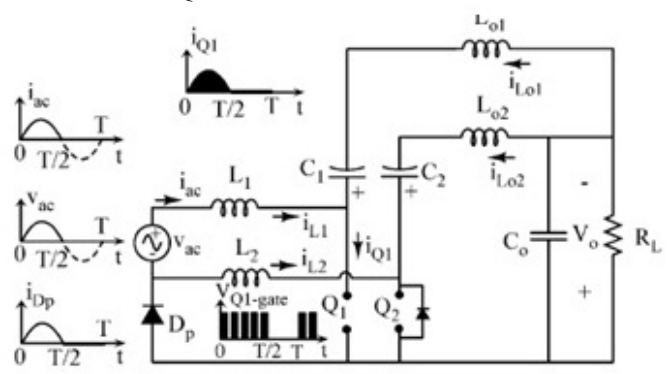

Figure 6: State 3 operation 


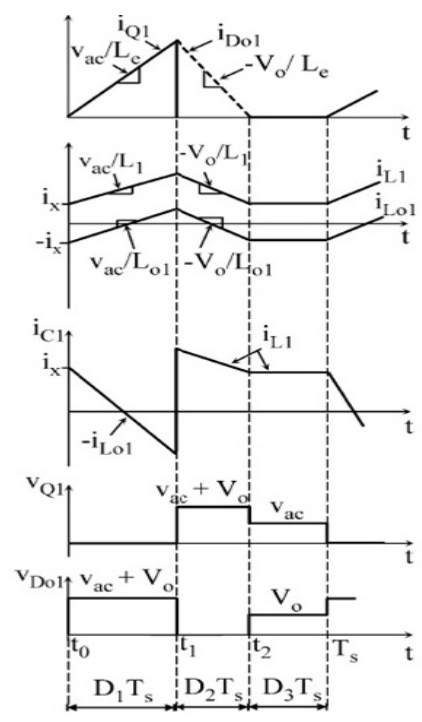

Figure 7: Switching waveform

III.

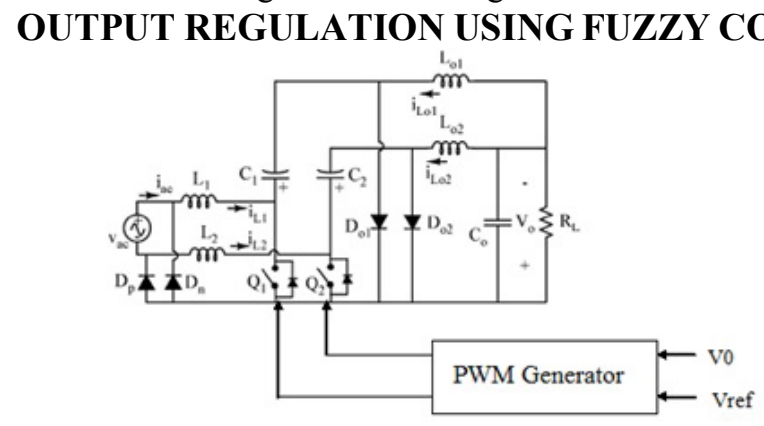

Figure 8: Basic output voltage regulation loop

Basic output voltage regulation loop is shown in figure 8. The output voltage can be controlled using closed loop control. A fuzzy control system is a control system based on fuzzy logic which is a mathematical system that analyzes analog input values in terms of logical variables that take on continuous values between 0 and 1 There are three steps for a fuzzy control- Fuzzification, Rule base, defuzzification. The fuzzy controller has two inputs, the error and change in error. Fuzzification is the first step in the fuzzy control. Here the membership functions are designed for the input. The process of converting a crisp input value to a fuzzy value is called fuzzification. Seven membership functions are taken with trapezoidal shape.

Seven fuzzy levels or sets are chosen for error (e), change in error (_e) and the output.

1)NL-Negative Large

2)NM-Negative Medium

3)NS-Negative Small

4)ZE-Zero Equal

5)PS-Positive Small

6)PM-Positive Medium

7)PL-Positive Large

Second step is to provide the rule controlling the working of a Fuzzy system. Fuzzy control rules are obtained from the analysis of the system behavior. Depending on the operating conditions different control laws can be made and this will improve the performance of the system. The fuzzy rules are based on the following criteria

1. When the output of the converter is far below the set point, the change of duty ratio must be large so as to bring the output to the set point quickly.

2. When the output of the converter is approaching the set point, a small change of duty ratio is necessary.

3. When the output of the converter is near the set point and is approaching it rapidly, the duty ratio must be kept constant so as to prevent overshoot. 
4. When the set point is reached and the output is still changing, the duty ratio must be changed a little bit to prevent the output from moving away.

5. When the set point is reached and the output is steady, the duty ratio remains unchanged.

6. When the output is above the set point, the sign of the change of duty ratio must be negative, and vice versa.

Fuzzy expert system is a combination of fuzzy set and the rule base.

The last step is Defuzzification. Here the fuzzy values are converted into crisp values.

Membership functions for error, change in error and output is shown in figures 9, 10, 11 respectively [12].

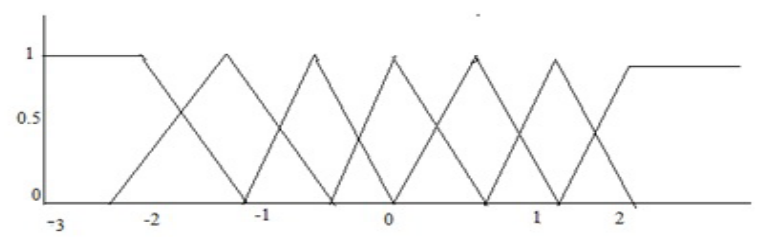

Figure 9: Membership function for error

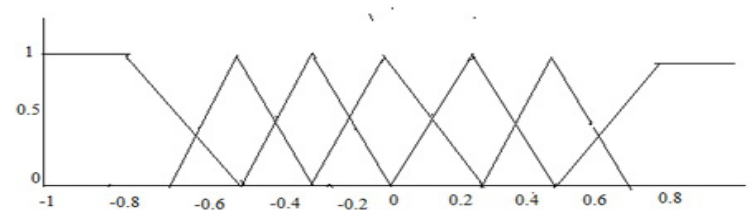

Figure 10: Membership function for change in error

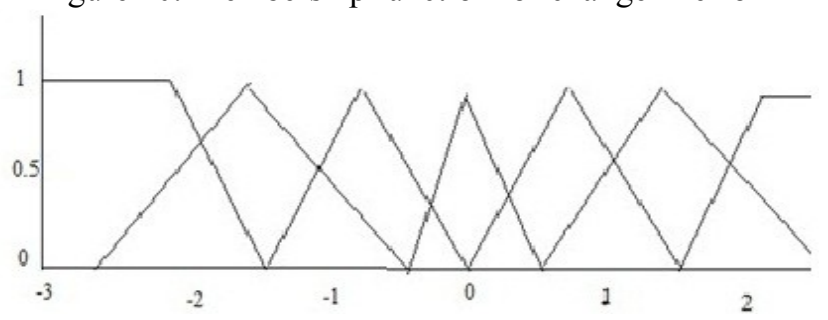

Figure 11: Membership function for output

\subsection{VOLTAGE CONVERSION RATIO \\ IV. ANALYSIS}

The voltage conversion ratio $\mathrm{M}$ in terms of the converter parameters can be obtained by applying the power balance principle. The average input power can be expressed as follows:

$$
<\mathrm{P}_{\text {in }}>_{\mathrm{T} / 2}=(2 / \mathrm{T}) \int\left(\mathrm{V}_{\mathrm{ac}}(\mathrm{t})<\mathrm{i}_{\mathrm{ac}}(\mathrm{t})>\mathrm{T}_{\mathrm{s}}\right) \mathrm{dt}
$$

where the notation $\langle:>$ represents the average value over the interval $\mathrm{x}$. Note that the input current in the positive half of the line cycle is the same as the inductor current $\mathrm{L}_{1}$. From figure 7 , it can be shown that the average input current over a switching cycle is given by

$$
<\mathrm{i}_{\mathrm{ac}}(\mathrm{t})>\mathrm{T}_{\mathrm{s}}=<\mathrm{i}_{\mathrm{L} 1}(\mathrm{t})>\mathrm{T}_{\mathrm{s}}=\mathrm{V}_{\mathrm{ac}}(\mathrm{t})=\mathrm{R}_{\mathrm{e}}
$$

where the quantity $\mathrm{R}_{\mathrm{e}}$ is defined as the emulated input resistance of the converter, and is given by

$$
\mathrm{R}_{\mathrm{e}}=\left(2 * \mathrm{~L}_{\mathrm{e}}\right) /\left(\mathrm{D}_{1}^{2} * \mathrm{~T}_{\mathrm{s}}\right)
$$

Evaluating 4 by using 5 and applying the power balance between the input and output ports, the desired voltage conversion ratio is

$$
\mathrm{M}=\left(\mathrm{V}_{0} / \mathrm{V}_{\mathrm{m}}\right)=\sqrt{ }\left(\mathrm{R}_{\mathrm{L}} /\left(2 * \mathrm{R}_{\mathrm{e}}\right)\right.
$$

\subsection{Boundaries Between CCM and DCM}

Referring to the diode $\mathrm{D}_{\mathrm{ol}}$ current waveform in figure 7, the DCM operation mode requires that the sum of the switch duty cycle and the normalized switch-OFF time length be less than one, Hence, the minimum and maximum values of $\mathrm{Ke}$-crit is given by

and

$$
\mathrm{Ke} \_ \text {crit } \_ \text {min }=1 /\left(2 *(\mathrm{M}+1)^{2}\right)
$$

$$
\text { Ke_crit_max }=1 /\left(2 * \mathrm{M}^{2}\right)
$$

Therefore, for values of $\mathrm{Ke}<\mathrm{K}_{-}^{-}$critmin, the converter always operates in DCM, and it operates in the continuous conduction mode $(\mathrm{CCM})$ for values of $\mathrm{Ke}>\mathrm{Ke}$ _crit_max. However for values of Ke_crit_min $<\mathrm{Ke}$ 
$<$ Ke_crit_max, the converter operates in both modes: CCM near the peak value of the input line voltage and DCM near the zero crossing of the input line voltage.

\subsection{Capacitor selection}

$\mathrm{C}_{1}$ and $\mathrm{C}_{2}$ must be chosen such that their steady-state voltages follow the shape of the rectified input ac line voltage waveform plus the output voltage with minimum switching voltage ripple as possible. Also, the values of $C_{1}$ and $C_{2}$ should not cause low-frequency oscillations with the converter inductors.

$$
\begin{aligned}
& \mathrm{f}_{1}<\mathrm{f}_{\mathrm{r}}<\mathrm{f}_{\mathrm{s}} \\
& \mathrm{f}_{\mathrm{r}}=1 /\left(2 * \pi * \sqrt{ }\left(\mathrm{C} 1{ }_{-}\left(\mathrm{L}_{1}+\mathrm{L}_{0}\right)\right)\right.
\end{aligned}
$$

The output capacitor $\mathrm{C}_{\mathrm{o}}$ needs to be sufficiently large to store minimum energy required for balancing the difference between the time varying input power and constant load power.

$$
\Delta \mathrm{v}_{\mathrm{o}}=\mathrm{V}_{\mathrm{o}} /\left(\mathrm{w} * \mathrm{R}_{\mathrm{L}} * \mathrm{C}_{\mathrm{o}}\right)
$$

\section{SIMULATED PERFORMANCE}

The circuit is simulated using MATLAB in Open loop mode and closed loop mode. PI controller and Fuzzy logic controller is employed to control the circuit. The parameters taken for the simulation are

1) RMS input voltage: $230 \mathrm{~V}$

2) Supply frequency: $50 \mathrm{HZ}$

3) Switching frequency: $50 \mathrm{KHZ}$

4) Output power: $150 \mathrm{~W}$

5) Output voltage: $48 \mathrm{~V}$

The input voltage and current waveform for the bridgeless cuk rectifier is shown in figure 12. The input current is tracking the input voltage. The power factor is 0.998 .

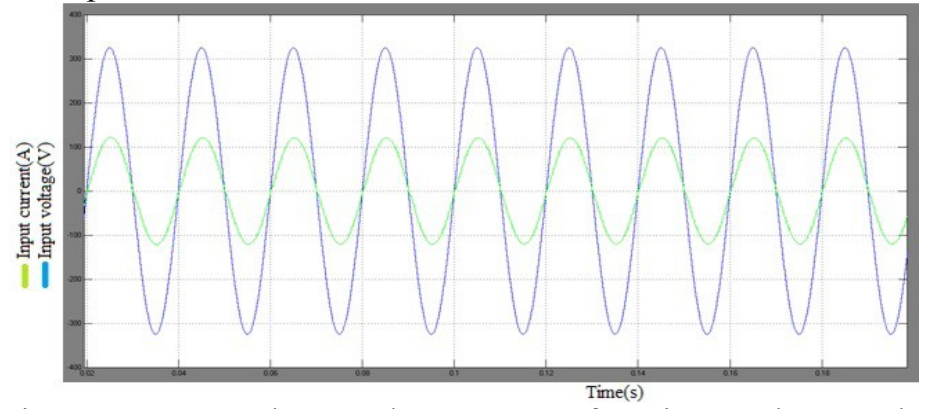

Figure 12: Input voltage and current waveform in open loop mode.

The THD obtained is $2 \%$. The inductor current waveforms are shown in figure 13. Current through Diode $\mathrm{D}_{\mathrm{p}}$ and $D_{n}$ is shown in figure 14. The output voltage is shown in figure 15. Output voltage waveform is constant at $48 \mathrm{~V}$. The output voltage regulation is done using Fuzzy controller. The output voltage for fuzzy controller is shown in the figure 16. The output voltage remains constant at $40 \mathrm{~V}$ which is the reference voltage. So the controller is tracking the reference voltage.

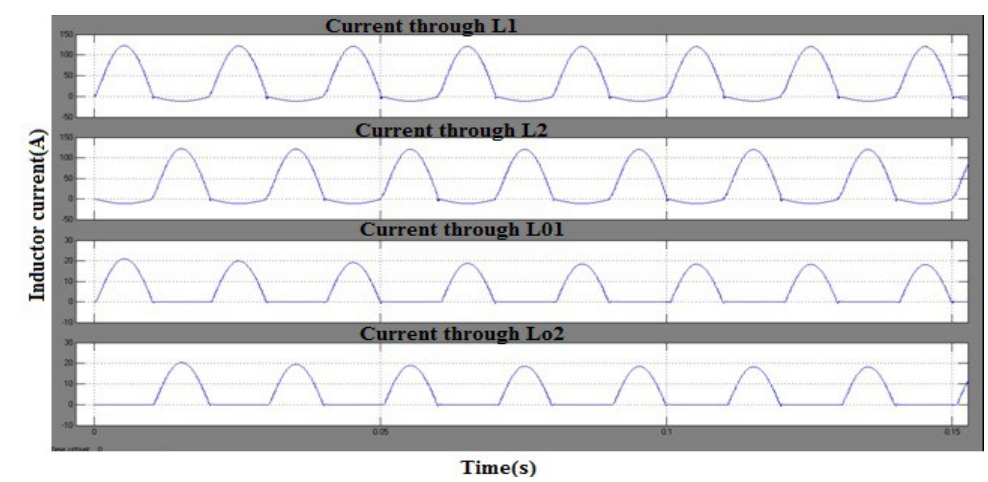

Figure 13: Inductor current waveforms in open loop mode 


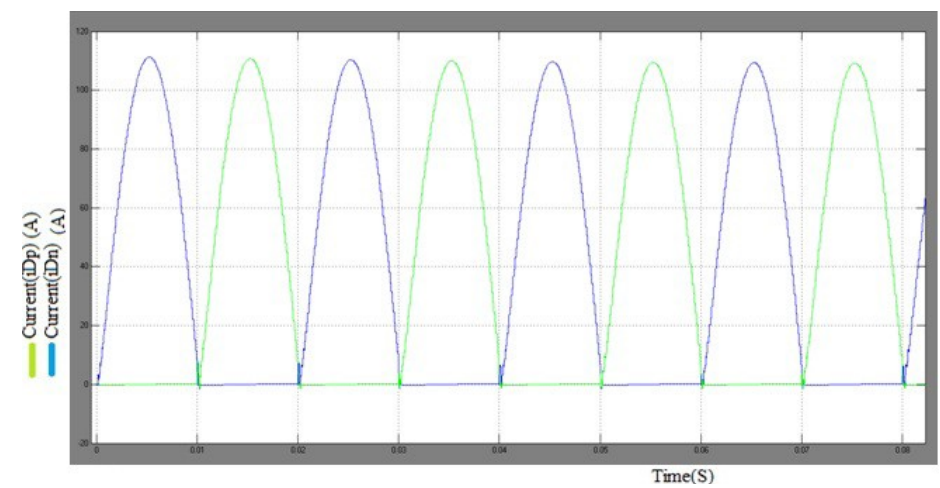

Figure 14: Diode currents $\left(i_{D p}\right.$ and $\left.i_{D n}\right)$ in open loop mode

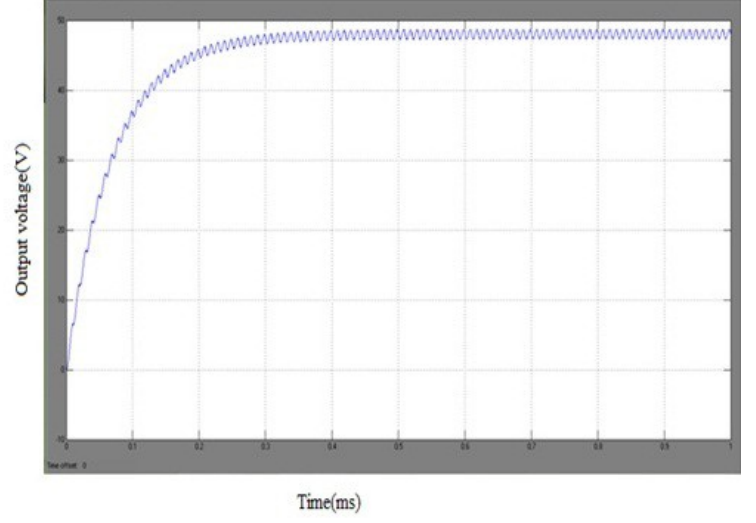

Figure 15: Output voltage in open loop mode

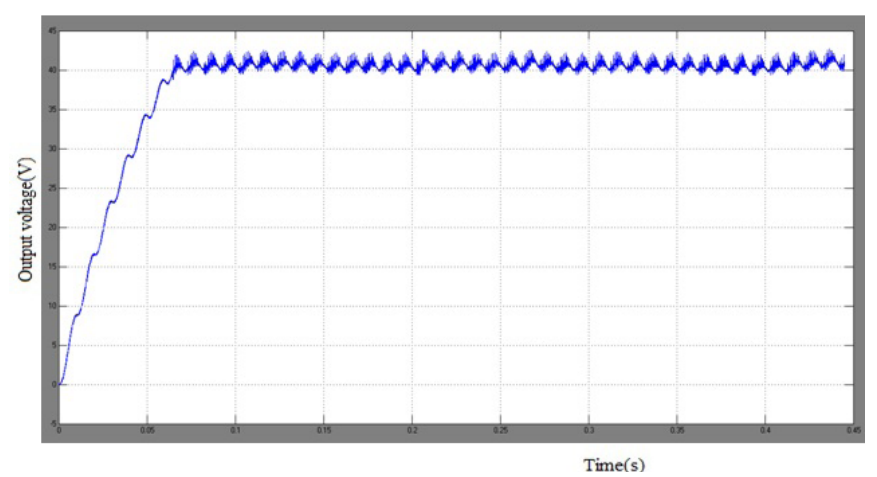

Figure 16: Output voltage waveform with fuzzy controller VI. CONCLUSION

A single phase AC to DC bridgeless CUK rectifier is discussed and simulated. Performance of the converter is verified by simulation and experimental results. The bridgeless CUK rectifier is simulated in MATLAB/SIMULINK in both open loop mode and closed loop mode. For the closed loop control Fuzzy controller is used. Fuzzy controller output settles in $1.5 \mathrm{~ms}$. To maintain the same efficiency, the circuit can operate with a higher switching frequency. Thus, additional reduction in the size of the PFC inductor and EMI filter could be achieved.

\section{REFERENCES}

[1] Abbas A. Fardoun, Esam H. Ismail, Ahmad J. Sabzali and Mustafa A. Al-Saffar, "New Efficient Bridgeless CUK Rectifiers for PFC Applications " IEEE transactions on power electronics vol. 27, no. 7, july 2012.

[2] A. Sabzali, E. H. Ismail, M. Al-Saffar, and A. Fardoun, "New bridgeless DCM sepic and CUK PFC rectifiers with low conduction and switching losses ", IEEE Trans. Ind. Appl, vol. 47, no. 2, pp. 873881, Mar./Apr. 2011..

[3] B. Lu, R. Brown, and M. Soldano, "Bridgeless PFC implementation using one cycle control technique ", Proc. IEEE Appl. Power Electron. Conf.,Mar. 2005, pp. 812817.

[4] Y. Jang and M. M. Jovanovic, “Bridgeless high-power-factor buck converter”, IEEE Trans. Power Electron.,vol. 26, no. 2, pp. 602611, Feb. 2011.

[5] K. Periyasamy, "Power Factor Correction Based On Fuzzy Logic Controller With Average Current-Mode For DC-DC Boost Converter”, (IJERA) ISSN: 2248-9622, Vol. 2, Issue 5, September- October 2012, pp.771-777. 
[6] M. R. Sahid, A. H. M. Yatim, Taufik Taufik, San Luis Obispo "A New AC-DC Converter Using Bridgeless SEPIC" IEEE transactions, 978-1-4244-5226-2/10/.

[7] L. Huber, Y. Jang, and M. Jovanovic "A Performance evaluation of bridgeless PFC boost rectifiers ", IEEE Trans. Power Electron, vol. 23, no. 3, pp. 13811390 , May 2008

[8] G. Ranganathan, L. Umanand, "New Efficient Bridgeless CUK Rectifiers for PFC Applications"

[9] D.S.L. Simonetti, J. Sebastiin, F. S. dos Reis and J. Uceda, "Design Criteria for Sepic and CUK Converters as Power Factor Preregulators in Discontinuous Conduction Mode"

[10] Domingos Savio Lyrio Simonetti, Javier Sebastian and Javier Uceda, "The Discontinuous Conduction Mode Sepic and CUK Power Factor Preregulators: Analysis and Design "IEEE Transactions on industrial electronics, vol. 44, no. 5, October 1997.

[11] G. Spiazzi, L. Rossetto, P. Mattavelli, "High-quality rectifier based on CUK converter in discontinuous capacitor voltage mode"

[12] Dr. T. Govindaraj and Rasila R, "Development of Fuzzy Logic Controller for D DC Buck Converters " Int J Engg Techsci Vol 2(2) 2011,192-198". 